\title{
RESULTS OF SURGICAL TREATMENT OF THYMOMAS WITH SPECIAL REFERENCE TO THE INVOLVED ORGANS
}

Meinoshin Okumura, $\mathrm{MD}^{\mathrm{a}}$

Shinichiro Miyoshi, MDa

Yukiyasu Takeuchi, MD $^{\mathrm{b}}$

Hyung-Eng Yoon, $\mathrm{MD}^{\mathrm{a}}$

Masato Minami, MDa

Shin-Ichi Takeda, $\mathrm{MD}^{\mathrm{a}}$

Yoshitaka Fujii, MD

Kazuya Nakahara, $\mathrm{MD}^{\mathrm{d}}$

Hikaru Matsuda, MD $^{a}$
Objective: The purpose of this study is to clarify the significance of the particular involved organ as a prognostic factor and its relation to other previously reported factors. Methods: The prognoses of 194 consecutive patients with thymoma who had undergone complete or subtotal resection were reviewed retrospectively. Survival was evaluated as actuarial freedom from tumor death. Analysis of prognostic factors was performed by the Kaplan-Meier method with the log rank test and Cox's proportional hazards model. Results: The Masaoka staging system and involvement of the great vessels were the independent prognostic factors in the entire study group; age, sex, histologic subtype, completeness of resection, association of myasthenia gravis, or involvement of other organs were not factors. The 10-year and 20-year survivals were $99 \%$ and $90 \%$ in stage $I, 94 \%$ and $90 \%$ in stage II, $88 \%$ and $56 \%$ in stage III, $30 \%$ and $15 \%$ in stage $I V a, 0 \%$ and $0 \%$ in stage $I V b, 93 \%$ and $83 \%$ in the absence of involvement of the great vessels, and $54 \%$ and $20 \%$ in the presence of it. Involvement of the great vessels was also the single independent prognostic factor in the patients with stage III disease although completeness of resection or involvement of other organs were not. The 10-year and 20-year survivals in patients with stage III disease were $97 \%$ and $75 \%$ in the absence of involvement of the great vessels, and $\mathbf{7 0 \%}$ and $29 \%$ in the presence of it. Conclusion: Although the Masaoka staging system is a valuable prognostic factor, the category of stage III is heterogeneous and consists of 2 groups with distinct prognoses depending on involvement of the great vessels. ( $J$ Thorac Cardiovasc Surg 1999;117:605-13)
$T^{\text {thens }}$ hymoma is a neoplasm arising from the epithelial cells of the thymus. ${ }^{1,2}$ Most thymomas are slowgrowing tumors, and tumor cells do not show a malignant appearance despite their invasive nature. ${ }^{1,2}$

The main therapeutic strategy in the treatment of thymoma is surgical resection, ${ }^{3-8}$ and the outcome of surgical treatment for this disease has been shown to depend on the local invasiveness of the tumor. ${ }^{9-14}$ The

From First Department of Surgery, Osaka University Medical School, ${ }^{a}$ Osaka; The Department of Surgery, Osaka Chuo Hospital, ${ }^{\mathrm{b}}$ Osaka; The Second Department of Surgery, Nagoya City University, Medical School, ${ }^{\mathrm{c}}$ Aichi; and the Department of Surgery, Ohtemae Hospital, ' Osaka, Japan.

Received for publication April 21, 1998; revisions requested June 17, 1998; revisions received Oct 16, 1998; accepted for publication Oct 19, 1998.

Address for reprints: Shinichiro Miyoshi, MD, First Department of Surgery, E-1, Osaka University Medical School, 2-2 Yamada-Oka, Suita-City, Osaka 565-0871, Japan.

Copyright (C) 1999 by Mosby, Inc.

$0022-5223 / 99 \$ 8.00+0 \quad 12 / 1 / 95294$ clinical staging system by Masaoka, which is based on the local extension of the tumor, ${ }^{15}$ has been shown to reflect the prognosis of thymoma, and the significance of this staging system as a prognostic factor has been confirmed by several other institutes. ${ }^{7,8,16,17}$ According to this staging system, however, cases that have involvement of the pericardium, the lung, the great vessels, or other surrounding organs are all classified as stage III disease if pleural dissemination or distant metastases are not associated. Thus which organ is involved by the tumor is left out of consideration in this staging system. There have not been, however, any reports concerning the importance of the particular involved organ as a prognostic factor, except for several studies focusing on the reconstruction of the great veins in thymoma ${ }^{18,19}$ and a study on thymic carcinoma. ${ }^{20}$ The significance of each involved organ as a prognostic factor and its relationship with other prognostic factors remain to be elucidated. To clarify this issue, we analyzed the long-term results of surgical treatment for thymoma with special 
Table I. Association of myasthenia gravis, completeness of resection, and involved organs according to the Masaoka staging system in patients with thymoma

\begin{tabular}{|c|c|c|c|c|c|c|c|c|c|}
\hline \multirow[b]{2}{*}{ Stage } & & \multicolumn{2}{|c|}{ Myasthenia gravis } & \multicolumn{2}{|c|}{ Resection } & \multicolumn{4}{|c|}{ Involved organ } \\
\hline & & $(+)$ & $(-)$ & Complete & Subtotal & Pleura & Pericardium & Lung & Great vessels \\
\hline I & 78 & 45 & 33 & 78 & 0 & 0 & 0 & 0 & 0 \\
\hline II & 44 & 33 & 11 & 44 & 0 & 31 & 0 & 0 & 0 \\
\hline III & 56 & 27 & 29 & 50 & 6 & 52 & 30 & 41 & 20 \\
\hline IVa & 10 & 4 & 6 & 0 & 10 & 10 & 8 & 8 & 6 \\
\hline $\mathrm{IVb}$ & 6 & 0 & 6 & 0 & 6 & 6 & 5 & 6 & 4 \\
\hline Tota1 & 194 & 109 & 85 & 172 & 22 & 99 & 43 & 55 & 30 \\
\hline
\end{tabular}

Table II. Survival of patients according to the Masaoka staging system

\begin{tabular}{llcrr} 
& \multicolumn{2}{c}{ Survival (95\% CI) } & \multicolumn{2}{c}{ Mean survival time $^{*}$} \\
\cline { 2 - 3 } \cline { 5 - 5 } Stage & \multicolumn{1}{c}{$10 y$} & $20 y$ & Years & $95 \%$ CI \\
\hline I & $99(96-101)$ & $90(78-102)$ & $35.67 \pm 1.35$ & $33.03-38.31$ \\
II & $94(87-102)$ & $90(79-101)$ & $28.05 \pm 1.20$ & $25.69-30.40$ \\
III & $88(78-97)$ & $56(36-77)$ & $21.71 \pm 1.51$ & $18.76-24.67$ \\
IVa & $30(2-58)$ & $15(-10-40)$ & $8.89 \pm 2.47$ & $4.04-13.74$ \\
IVb & 0 & & $2.28 \pm 0.61$ & $1.08-3.48$ \\
\hline
\end{tabular}

${ }^{*}$ Mean $\pm \mathrm{SE}$.

reference to the involved organs with other previously reported prognostic factors, based on the retrospective review of 194 consecutive patients who underwent surgical treatment at our institute.

\section{Patients and methods}

Patients. Thymoma is defined as a tumor that originates from the thymic epithelial cells but does not show an apparent malignant morphologic condition. ${ }^{1,2}$ The epithelial tumors that are obviously malignant cytologically were referred to as thymic carcinomas in this study, according to classification of thymic epithelial tumors by Snoover and associates $^{21}$ and Suster and Rosai. ${ }^{22}$ Therefore malignant lymphomas, germ cell tumors, carcinoids, thymic carcinomas, and thymic hyperplasia were excluded in this study.

The extent of the tumor was evaluated before the operation by routine chest radiographic examination, conventional chest computed tomography, and recently by magnetic resonance imaging. A total of 208 patients with thymoma were treated at Osaka University Hospital from January 1957 to June 1996. Four patients who had received their initial surgical treatment at other institutes and another 10 patients who underwent a biopsy only were excluded from this study. Accordingly, the study group consisted of 194 patients who underwent complete or subtotal resection at our institute.

There were 107 male and 87 female patients. The age of the patients ranged from 10 to 74 years, and the median age was 45 years (mean \pm standard deviation: $45.5 \pm 13.0$ years). Myasthenia gravis was associated in 109 patients $(56.2 \%)$.
Other associated diseases were pure red cell aplasia (7 patients), rheumatoid arthritis (2 patients), systemic lupus erythematosus ( 1 patient), Graves' disease ( 1 patient), Hashimoto's disease (1 patient), Sjögren syndrome (1 patient), and pemphigus vulgaris (1 patient).

The thymomas were classified histologically on the basis of the predominance of epithelial cells or lymphocytes according to the proposal of Bernatz and associates, ${ }^{23}$ and 53, 38 , and 102 thymomas were classified into the predominantly lymphocytic type, the predominantly epithelial type, and the mixed lymphoepithelial type, respectively. The histologic subtype in 1 patient with stage III disease was not determined because of extensive necrosis induced by preoperative chemotherapy.

The involved organs in each patient were confirmed by critical review of the records of operation. The great vessels refer to the brachiocephalic veins, the superior vena cava, or the aorta in this study.

Association of myasthenia gravis, completeness of resection, and the involved organs according to the Masaoka staging system are presented in Table I. In the patients with stage IV disease, resection was judged as subtotal even when all the lesions appeared to be removed.

As a postoperative adjuvant therapy, radiation to the mediastinum was administered to all patients until 1985; since 1986 , radiation to the mediastinum has been limited to those patients with invasive thymoma, including stage II, III, and IV diseases. Chemotherapy was generally performed in patients with stage IV disease. Patients with stage III disease 
whose surgical treatment was incomplete resection also received adjuvant chemotherapy.

The outcome of patients was confirmed by the physicians' records and direct contact with patients by telephone. Postoperative follow-up study was performed by annual chest radiographic examination; when tumor recurrence was suspected, chest computed tomography was added. In recent cases, magnetic resonance imaging was also used for further evaluation. Seven patients in the study group required a second surgical treatment for recurrent tumors afterward. The follow-up period ranged from 2 months (death from myasthenia gravis) to 38 years, and the median follow-up period was 10.3 years (mean $\pm \mathrm{SD} ; 11.3 \pm 7.8$ years). Sixty-six patients died during the follow-up period. Although 32 patients died of a tumor, 34 patients died of accidents or other diseases including crisis of myasthenia gravis (12 patients). One hundred patients, including 4 with tumor recurrence, were alive in January 1998. Nineteen patients were alive at some point between 1991 and 1997. The remaining 9 patients were lost to follow-up before 1991 at $23,23,15,13,10,8,7$, and 7 years, and 3 months after operation, respectively.

Statistical analysis. To focus on the oncologic behavior of thymoma, the patients who died of other diseases or accidents were dealt with as drop-out cases at the time of the event. In this study therefore survival refers to freedom from tumor death. The actuarial survivals were calculated with the method of Kaplan and Meier. The statistical difference of survival was examined with the log rank test. The relative importance of various prognostic factors for postoperative survival as identified by multivariable analysis was analyzed with Cox's proportional hazards model with the forward stepwise method. Association between categoric variables was examined by the $\chi^{2}$ test or Fisher's exact test. The statistical difference of the mean value was examined by the Student $t$ test. Statistical analyses were performed with the commercially available personal computer program SPSS (SPSS, Inc, Chicago, Ill).

\section{Results}

Factors associated with survival of all patients. The survival curves according to the Masaoka staging system are shown in Fig 1. The 10- and 20-year survivals and the mean survival times are also presented in Table II. There was a significant difference in survival between stage I and stage III $(P=.002)$, between stage I and stage IVa $(P<.0001)$, between stage I and stage IVb $(P<.0001)$, between stage II and stage IVa $(P<$ $.0001)$, between stage II and stage IVb $(P<.0001)$, between stage III and stage IVa $(P<.0001)$, between stage III and stage IVb $(P<.0001)$, and between stage IVa and stage IVb $(P=.04)$. There was a marginal difference between stage II and stage III $(P=.06)$.

Next, we examined the significance of other prognostic factors such as age, sex, histologic subtype, completeness of resection, involvement of the surrounding

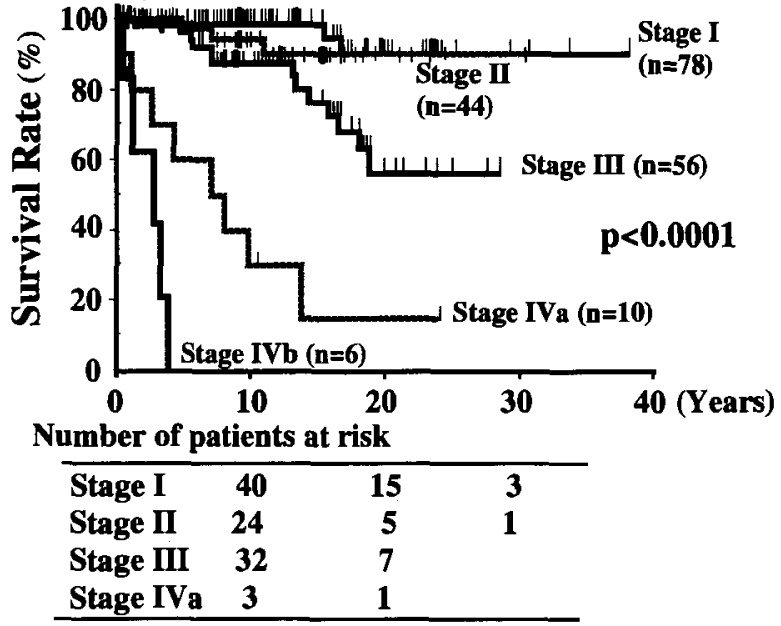

Fig 1. Survival according to the Masaoka staging system. The patients who died of other diseases or accidents were dealt with as drop-out cases at the time of the event; thus survival refers to actuarial freedom from tumor death. The number of patients at risk at 10,20, and 30 years after operation is presented under the curves.

organs, and association of myasthenia gravis, by univariate analysis. There was a significant difference in survival according to completeness of resection $(P<$ $.0001)$, involvement of the pleura $(P<.0001)$, involvement of the pericardium $(P<.0001)$, involvement of the lung $(P<.0001)$, or involvement of the great vessels $(P$ $<.0001$ ). Table III shows 10 - and 20 -year survivals and mean survival times according to these factors. The survival curves according to completeness of resection and involvement of the great vessels are shown in Figs 2 and 3 , respectively. On the other hand, there was no significant difference in survival according to age ( $<45$ years vs $>45$ years; $P=.50)$, sex $(P=.42)$, or histologic subtype $(P=.55)$. There was a marginal difference in survival between the patients with myasthenia gravis and those without it $(P=.07)$.

By multivariate analysis with Cox's proportional hazards model, Masaoka's clinical stage and the involvement of the great vessels were shown to be the independent factors to determine postoperative survival. The $P$ value, the relative risk, and $95 \%$ confidence interval (CI) of each factor are presented in Table IV. Survival did not, however, depend on age ( $P$ $=.31)$, sex $(P=.45)$, histologic subtype $(P=.74)$, association of myasthenia gravis $(P=.32)$, completeness of resection $(P=.16)$, involvement of pleura $(P=$ $.96)$, involvement of the pericardium $(P=.48)$, or involvement of the lung $(P=.46)$ according to the multivariate analysis, although the univariate analyses 


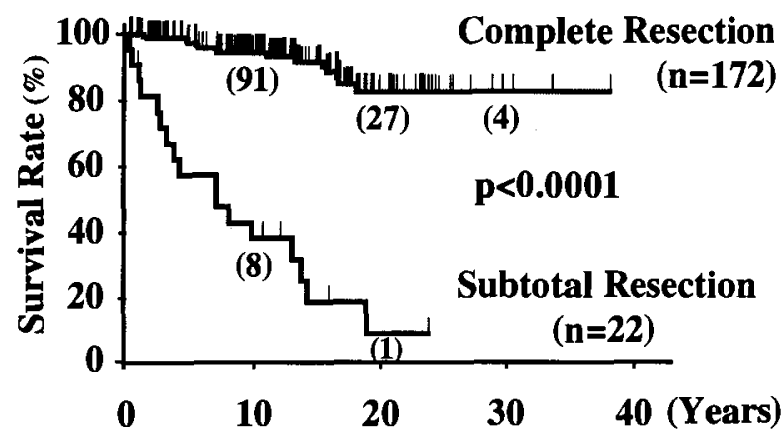

Fig 2. Survival according to completeness of resection. Survival refers to actuarial freedom from tumor death. The numbers in parentheses below each curve denote the number of patients at risk at a given time point after operation.

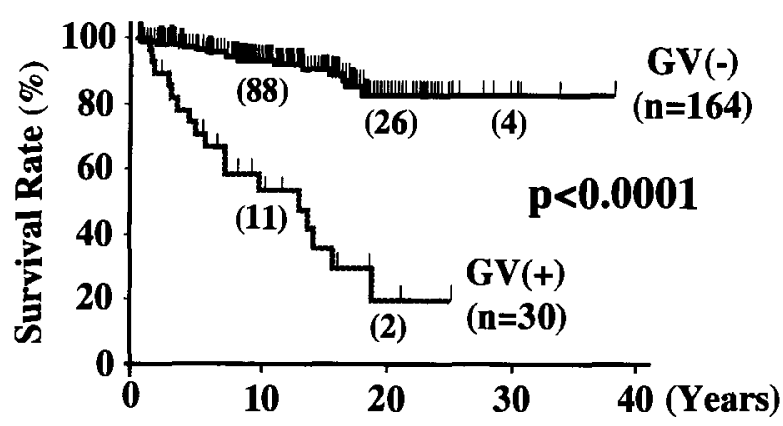

GV : Involvement of the great vessels

Fig 3. Survival according to the presence or absence of involvement of the great vessels ( $G V$ ). Survival refers to actuarial freedom from tumor death. The numbers in parentheses below each curve denote the number of patients at risk at a given time point after operation.

Table III. Survival of patients according to completeness of resection, involved organ, and association of myasthenia gravis

\begin{tabular}{|c|c|c|c|c|c|}
\hline \multirow[b]{2}{*}{ Factor } & \multicolumn{2}{|c|}{ Survival $(95 \% C I)$} & \multicolumn{3}{|c|}{ Mean survival time ${ }^{*}$} \\
\hline & $10 y$ & $20 y$ & Years & $95 \% C I$ & $\mathrm{P}$ value \\
\hline \multicolumn{6}{|l|}{ Resection } \\
\hline Complete & $94(90-98)$ & $82(73-91)$ & $33.48 \pm 1.12$ & $31.28-35.68$ & \\
\hline Subtotal & $38(17-59)$ & $10(-7-26)$ & $9.11 \pm 1.67$ & $5.83-12.39$ & $<.0001$ \\
\hline \multicolumn{6}{|l|}{ Great vessels } \\
\hline Not involved & $93(89-98)$ & $83(74-92)$ & $33.42 \pm 1.14$ & $31.17-35.66$ & \\
\hline Involved & $54(34-73)$ & $20(-1-41)$ & $12.19 \pm 1.74$ & $8.78-15.59$ & $<.0001$ \\
\hline \multicolumn{6}{|l|}{ Pleura } \\
\hline Not involved & $98(94-101)$ & $91(81-100)$ & $35.66 \pm 1.18$ & $33.34-37.98$ & \\
\hline Involved & $77(68-86)$ & $54(38-69)$ & $20.96 \pm 1.40$ & $18.21-23.71$ & $<.0001$ \\
\hline \multicolumn{6}{|l|}{ Pericardium } \\
\hline Not involved & $94(89-98)$ & $80(70-90)$ & $32.89 \pm 1.26$ & $30.42-35.35$ & \\
\hline Involved & $65(49-81)$ & $42(21-63)$ & $15.15 \pm 1.52$ & $12.18-18.13$ & $<.0001$ \\
\hline \multicolumn{6}{|l|}{ Lung } \\
\hline Not involved & $95(91-99)$ & $86(78-95)$ & $34.32 \pm 1.15$ & $32.08-36.57$ & \\
\hline Involved & $69(56-82)$ & $43(25-61)$ & $17.73 \pm 1.65$ & $14.50-20.95$ & $<.0001$ \\
\hline \multicolumn{6}{|l|}{ Myasthenia gravis } \\
\hline Not Associated & $82(73-90)$ & $69(55-83)$ & $28.62 \pm 1.96$ & $24.78-32.45$ & \\
\hline Associated & $91(85-97)$ & $73(60-87)$ & $28.06 \pm 1.31$ & $25.49-30.63$ & .07 \\
\hline
\end{tabular}

${ }^{*}$ Mean \pm SE.

Table IV. Independent prognostic factors according to Cox's proportional hazards model

\begin{tabular}{lccc}
\hline Factor & Relative risk & $95 \%$ CI & P value \\
\hline $\begin{array}{l}\text { Involvement of the } \\
\text { great vessels }\end{array}$ & 2.4862 & $1.1621-5.3189$ & .02 \\
\begin{tabular}{l} 
Masaoka stage \\
\hline
\end{tabular} & 3.4399 & $2.1891-5.4055$ & $<.0001$ \\
\hline
\end{tabular}

showed that the latter 4 factors were related with survival (Table III).

Factors associated with survival of patients with stage III disease. The significance of the prognostic factors examined earlier were also assessed by both univariate and multivariate analyses in patients with stage III disease.

Table $\mathrm{V}$ denotes 10 - and 20-year survivals and the mean survival time of patients with stage III disease, according to the prognostic factors examined. By univariate analysis, there was a significant difference in the survival of patients with stage III disease according to completeness of resection and involvement of the great vessels. There was no statistical difference, however, in survival of patients with stage III disease according to involvement of the pleura, the pericardi- 
Volume 117, Number 3

Table V. Survival of patients with stage III disease according to completeness of resection, involved organ, and association of myasthenia gravis

\begin{tabular}{|c|c|c|c|c|c|}
\hline \multirow[b]{2}{*}{ Factor } & \multicolumn{2}{|c|}{ Survival $(95 \% \mathrm{CI})$} & \multicolumn{3}{|c|}{ Mean survival time ${ }^{*}$} \\
\hline & $10 y$ & $20 y$ & Years & $95 \% C I$ & $\mathbf{P}$ value \\
\hline \multicolumn{6}{|l|}{ Resection } \\
\hline Complete & $88(79-98)$ & $68(49-87)$ & $23.21 \pm 1.52$ & $20.25-26.17$ & \\
\hline Subtotal & $83(54-113)$ & 0 & $14.68 \pm 2.06$ & $10.64-18.71$ & .04 \\
\hline \multicolumn{6}{|l|}{ Great vessels } \\
\hline Not involved & $97(91-103)$ & $75(52-98)$ & $25.03 \pm 1.52$ & $22.05-28.02$ & \\
\hline Involved & $70(48-92)$ & $29(0-59)$ & $15.36 \pm 2.05$ & $11.34-19.39$ & .003 \\
\hline \multicolumn{6}{|l|}{ Pleura } \\
\hline Not involved & 100 & 100 & ND & ND & \\
\hline Involved & $86(76-97)$ & $54(32-75)$ & $21.28 \pm 1.58$ & $18.18-24.37$ & .31 \\
\hline \multicolumn{6}{|l|}{ Pericardium } \\
\hline Not involved & $91(79-103)$ & $59(32-86)$ & $22.56 \pm 1.96$ & $18.72-26.40$ & \\
\hline Involved & $85(70-99)$ & $57(29-85)$ & $18.59 \pm 1.62$ & $15.42-21.75$ & .52 \\
\hline \multicolumn{6}{|l|}{ Lung } \\
\hline Not involved & $93(79-106)$ & $70(29-110)$ & $20.92 \pm 2.45$ & $16.11-25.72$ & \\
\hline Involved & $86(74-97)$ & $54(31-76)$ & $21.26 \pm 1.71$ & $17.91-24.60$ & .59 \\
\hline \multicolumn{6}{|l|}{ Myasthenia gravis } \\
\hline Not associated & $83(68-98)$ & $70(48-91)$ & $22.51 \pm 2.08$ & $18.43-26.59$ & \\
\hline Associated & $92(80-102)$ & $44(11-76)$ & $20.50 \pm 1.88$ & $16.81-24.19$ & .85 \\
\hline
\end{tabular}

$N D$, Not calculated, because all the patients were alive at the last follow-up. ${ }^{*}$ Mean \pm SE.

um, or the lung or association of myasthenia gravis, unlike the results obtained by univariate analyses from all patients (Table III). The survival curves of patients with stage III disease according to presence or absence of involvement of the great vessels are shown in Fig 4.

Multivariate analysis was again adopted to determine the independent prognostic factors in patients with stage III disease. Similarly to the results obtained in the entire study group (Table IV), involvement of the great vessels was the only independent factor to determine postoperative survival with the relative risk of 4.936 (95\% CI, 1.517 to $16.061 ; P=.008$ ), although association of myasthenia gravis $(P=.42)$, completeness of resection $(P=.69)$, involvement of the pleura $(P=.16)$, involvement of the pericardium $(P=.99)$, or involvement of the lung $(P=.47)$ were not independent factors.

Table VI denotes the relation of involvement of the great vessels to other factors. Although there was no significant relation between involvement of the great vessels and of each age, sex, association of myasthenia gravis, histologic subtype, or involvement of other organs, there was a significant relation between the involvement of the great vessels and completeness of resection $(P=.001)$.

Finally, we examined the relation between involvement of the great vessels and tumor recurrence. Fourteen of 20 patients with stage III disease with involvement of the great vessels underwent complete resection. Seven $(50 \%)$ of these 14 patients experienced tumor recurrence, and distant metastases to the lung, the liver, or the kidney were found in 5 patients. All 36 patients with stage III disease with no involvement of the great vessels were treated by complete resection; tumor recurrence was experienced by only 6 of these patients $(17 \%)$.

\section{Discussion}

Prognostic factors determining the outcome of surgical treatment for thymoma have been extensively discussed but are still controversial., 7,8,16,17,24 This seems partly because thymoma is an uncommon and slowgrowing tumor. This forces the investigators studying the prognostic factors to observe the patients for a much longer follow-up period compared with other malignant diseases, and this condition inevitably brings about the high incidence of patient death from other diseases during the follow-up period. Additionally, associated autoimmune diseases such as myasthenia gravis and pure red cell aplasia are sometimes life-threatening. For this reason, as many as 34 of 66 postoperative deaths $(52 \%)$ were not related to the tumor's progress in our series. Therefore the analytic method used in this study and other reports, ${ }^{6,17}$ in which patients who died of the other diseases or accidents were dealt with as the dropout cases, is supposed to be justified when focusing on the oncologic behavior of thymoma.

Another important issue in the research of thymomas 
Table VI. Relation between involvement of the great vessels and other factors

\begin{tabular}{|c|c|c|c|c|c|c|c|}
\hline \multirow[b]{2}{*}{ Factor } & \multicolumn{3}{|c|}{ Great vessels not involved ( 36 patients) } & \multicolumn{3}{|c|}{ Great vessels involved (20 patients) } & \multirow[b]{2}{*}{$\mathrm{P}$ value } \\
\hline & No. & Proportion & $95 \% C l$ & No. & Proportion & $95 \% \mathrm{Cl}$ & \\
\hline Age (y) & $44.5 \pm 11.4^{*}$ & & $40.8-48.2$ & $46.9 \pm 12.2^{*}$ & & $41.5-52.3$ & .48 \\
\hline \multicolumn{8}{|l|}{ Sex } \\
\hline Male & 22 & 61 & $45-77$ & 10 & 50 & $28-72$ & \\
\hline Female & 14 & 39 & $23-55$ & 10 & 50 & $28-72$ & .60 \\
\hline \multicolumn{8}{|c|}{ Myasthenia gravis } \\
\hline Associated & 16 & 44 & $28-60$ & 11 & 55 & $33-77$ & \\
\hline Not associated & 20 & 56 & $40-72$ & 9 & 45 & $23-67$ & .63 \\
\hline \multicolumn{8}{|c|}{ Histologic condition } \\
\hline Epithelial & 9 & 26 & $11-41$ & 4 & 20 & $2-38$ & .75 \\
\hline Mixed & 20 & 57 & $40-74$ & 11 & 55 & $33-77$ & \\
\hline Lymphocytic & 6 & 17 & $4-30$ & 5 & 25 & $5-45$ & \\
\hline \multicolumn{8}{|l|}{ Pleura } \\
\hline Not involved & 2 & 6 & $-2-14$ & 2 & 10 & $-4-24$ & \\
\hline Involved & 34 & 94 & $86-102$ & 18 & 90 & $76-104$ & .61 \\
\hline \multicolumn{8}{|l|}{ Pericardium } \\
\hline Not involved & 19 & 53 & $36-70$ & 7 & 35 & $14-56$ & \\
\hline Involved & 17 & 47 & $30-64$ & 13 & 65 & $44-86$ & .32 \\
\hline \multicolumn{8}{|l|}{ Lung } \\
\hline Not involved & 10 & 28 & $13-43$ & 5 & 25 & $5-45$ & \\
\hline Involved & 26 & 72 & $57-87$ & 15 & 75 & 55-95 & 1.00 \\
\hline \multicolumn{8}{|l|}{ Resection } \\
\hline Complete & 36 & 100 & $100-100$ & 14 & 70 & 49-91 & \\
\hline Subtotal & 0 & 0 & $0-0$ & 6 & 30 & $9-51$ & .001 \\
\hline
\end{tabular}

${ }^{*}$ Mean \pm SD.

is the confusion between thymoma and thymic carcinoma. Levine and Rosai ${ }^{2}$ first classified invasive thymomas into 2 categories: category I malignant thymoma, which have no or minimal cytologic atypia, and category II malignant thymoma, which are obviously malignant cytologically. Category II malignant thymoma was later defined as thymic carcinoma by this group. ${ }^{2.21,22}$ More recently, Müller-Hermelink and associates ${ }^{25,26}$ proposed a new classification of thymoma based on the origin of the neoplastic epithelial cell, that is, the cortical type or the medullary type. This group later added another category and named well-differentiated thymic carcinoma. ${ }^{27}$ Thymic tumors of this category are characterized by a predominance of epithelial cells, an epidermoid differentiation with slight to moderate cytologic atypia, the constant presence of interepithelial immature cortical thymocytes, lobular growth, and formation of epithelial palisades around perivascular spaces. On the other hand, the most recent classification of thymic epithelial tumors proposed by Shimosato and Mukai ${ }^{28}$ takes into consideration whether the neoplastic epithelial cells still hold the thymic epithelial function to induce immature $\mathbf{T}$ cells from bone marrow-derived T-cell precursors; the tumors that retain this function are defined as thymoma although thymic carcinomas do not hold it any more. The fact that Müller-Hermelink and associates' welldifferentiated thymic carcinoma contains immature cortical thymocytes suggests that this tumor still holds the thymic epithelial function. In this sense, Shimosato and Mukai included Müller-Hermelink and associates' well-differentiated thymic carcinoma in a group of atypical thymomas. The high incidence of association with myasthenia gravis in these tumors also suggests the biologic analogy to benign thymomas. In this study, thymic carcinomas were defined according to the definition of Rosai and associates ${ }^{21,22}$ and were excluded from the study group. On the other hand, MüllerHermelink and associates' well-differentiated thymic carcinoma were included in the study group, following Shimosato and Mukai's definition.

Under these conditions, the univariate analyses in this study demonstrated that the Masaoka staging system and completeness of resection are significant prognostic factors, consistent with previous reports. . $^{5,14-17}$ According to the Masaoka staging system, the prognosis of patients with stage I and II diseases was extremely good with a 30-year survival of $90 \%$ (Fig 1). On the contrary, the survival of patients with stage III, IVa, or $\mathrm{IVb}$ disease deteriorates as the stage progresses. The 
multivariate analysis also revealed that the Masaoka staging system is a significant factor. Thus the Masaoka staging system is demonstrated to be highly valuable as a prognostic factor of thymoma when survival was evaluated in terms of freedom from tumor death. Although completeness of resection was also shown to be a significant prognostic factor by univariate analysis (Fig 2), as reported by other investigators, ${ }^{6,16}$ it no longer appeared as an independent factor by multivariate analysis. In place of it, involvement of the great vessels was chosen as an independent prognostic factor along with Masaoka staging system (Table IV). Furthermore, although univariate analyses showed that survival depends on involvement of each surrounding organ such as the pleura, the pericardium, the lungs, or the great vessels (Table III), none of these factors were considered as an independent prognostic factor by multivariate analysis. These results are presumed to come from the situation in which the Masaoka staging system or involvement of the great vessels are related to each of the remaining factors.

Association of myasthenia gravis was also reported to be one of the prognostic factors. This was derived from perioperative deaths from myasthenia gravis in the earlier days..$^{29}$ However, association of myasthenia gravis is no longer considered an adverse factor in survival. ${ }^{24}$ Conversely, Maggi and associates ${ }^{7}$ reported that association of myasthenia gravis contributes to early discovery of associated thymoma, thus allowing a better survival for patients with thymoma associated with myasthenia gravis compared with those not associated with it. Because our institute is one of the centers for surgical treatment of myasthenia gravis in Japan, this seems to result in the high incidence of association with myasthenia gravis in this series and is presumed to have presented the result similar to Maggi and associates. By multivariate analysis, however, association of myasthenia gravis was no longer an independent prognostic factor. This might come from the higher proportion of patients with earlier stages when associated with myasthenia gravis. Actually, in this series, the proportion of patients with stage I or II disease was $71.6 \%$ in cases associated with myasthenia gravis and $51.7 \%$ in cases not associated with it (Table I).

Because the category of stage III according to the Masaoka staging system seems to be highly heterogeneous in terms of the involved organs and the completeness of resection, as pointed out by Rea and associates, ${ }^{30}$ univariate and multivariate analyses were again performed according to those prognostic factors in patients with stage III disease. Although both completeness of resection and involvement of the great ves-

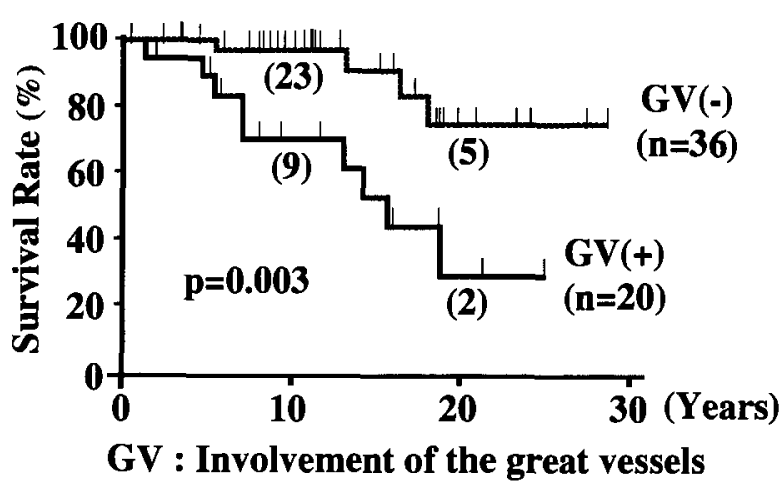

Fig 4. Survival of patients with stage III disease according to the presence or absence of involvement of the great vessels $(G V)$. Survival refers to actuarial freedom from tumor death. The numbers in parentheses below each curve denote the number of patients at risk at a given time point after operation.

sels were considered to be the prognostic factors by univariate analysis, the multivariate analysis demonstrated that involvement of the great vessels is the single independent prognostic factor. The significant relation between completeness of resection and involvement of the great vessels shown in Table VI explains that these 2 factors are well linked. Actually, 6 of 20 patients with involvement of the great vessels underwent subtotal resection. Even in the remaining 14 patients who underwent complete resection, tumor recurrence occurred in 7 patients $(50 \%)$, and the relapsed sites included distant organs in 5 patients. Thus involvement of the great vessels seems to have a greater adverse effect on survival than completeness of resection. Postoperative radiation with or without chemotherapy was the main strategy for adjuvant therapy to those patients with involvement of the great vessels in our series. Rea and associates ${ }^{30}$ and Macchiarini and associates ${ }^{31}$ attempted a prospective, single-arm treatment study investigating induction chemotherapy with surgical intervention. Considering the effectiveness in reduction of tumor by induction chemotherapy, this approach seems to be recommended for cases of highly invasive stage III thymoma, especially with involvement of the great vessels.

Blumberg and associates ${ }^{20}$ reported the prognosis of thymic carcinomas and determined that involvement of the great vessels is an independent prognostic factor. This was quite similar to our result. On the other hand, the Masaoka staging system had no impact on survival in the series of Blumberg and associates. The inconsistency between the results from our series and Blumberg and associates might be derived from the difference 
between our patient group and Blumberg and associates patient group, which is composed mostly of thymic carcinomas as described by Rosai and associates. $^{21,22}$ The difference of clinical implication of the Masaoka staging system between these 2 studies might reflect the oncologic distinction between thymomas and thymic carcinomas.

In conclusion, the Masaoka staging system and involvement of the great vessels were independent prognostic factors in our series of thymomas. Involvement of the great vessels was also an independent prognostic factor in patients with stage III disease. Thus the category of stage III disease in the Masaoka staging system is a heterogeneous group, consisting of 2 subgroups with distinct prognosis depending on involvement of the great vessels. Involvement of the great vessels was suggested to be an essential factor in determining the therapeutic modality for stage III thymoma.

We thank Dr Toshiro Nishida for help in statistical analysis.

\section{REFERENCES}

1. Rosai J, Levine GD. Tumors of the thymus. Washington [DC]: Armed Forces Institute of Pathology; 1976.

2. Levine GD, Rosai J. Thymic hyperplasia and neoplasia: a review of current concepts. Hum Pathol 1978;9:495-515.

3. Weissberg D, Goldberg M, Pearson FG. Thymoma. Ann Thorac Surg 1973;16:141-7.

4. Shamji F, Pearson FG, Todd TRJ, Ginsberg RJ, Ilves R, Cooper JD. Results of surgical treatment for thymoma. J Thorac Cardiovasc Surg 1984;87:43-7.

5. Cohen DJ, Ronnigen LD, Graeber GM, et al. Management of patients with malignant thymoma. J Thorac Cardiovase Surg 1984;87:301-7.

6. Nakahara K, Ohno K, Hashimoto J, et al. Thymoma: results with complete resection and adjuvant postoperative irradiation in 141 consecutive patients. J Thorac Cardiovasc Surg 1988;95:1041-7.

7. Maggi G, Casadio C, Cavallo A, Cianci R, Molinatti M, Ruffini E. Thymoma: results of 241 operated cases. Ann Thorac Surg 1991;51:152-6.

8. Blumberg D, Port JL, Weksler B, et al. Thymoma: a multivariate analysis of factors predicting survival. Ann Thorac Surg 1995; 60:908-14.

9. Batata MA, Martini N, Huvos AG, Aguilar R1, Beattie EJ Jr. Thymoma: clinicopathologic features, therapy, and prognosis. Cancer 1974;34:389-96.

10. Salyer WR, Eggleston JC. Thymoma: a clinical and pathological study of 65 cases. Cancer 1976;37:229-49.

11. LeGolvan DP, Abell MR. Thymomas. Cancer 1977;39:2142-57.

12. Bergh NP, Gatzinski P, Larsson S, Lundin P, Ridell B. Tumors of the thymus and thymic region. I. Clinicopathological studies on thymomas. Ann Thorac Surg 1978;25:91-8.

13. Verley JM, Hollmann KH. Thymoma: a comparative study of clinical stages, histologic features, and survival in 200 cases. Cancer 1985;55:1074-86.

14. Gamondes JP, Balawi A, Greenland T, et al. Seventeen years of surgical treatment of thymoma: factors influencing survival. Eur J Cardiothorac Surg 1991;5:124-31.

15. Masaoka A, Monden Y, Nakahara K, Tanioka T. Follow-up study of thymomas with special reference to their clinical stages. Cancer 1981;48:2485-92.

16. Regnard J-F, Magdeleinat P, Dromer C, et al. Prognostic factors and long-term results after thymoma resection: a series of 307 patients. J Thorac Cardiovasc Surg 1996;1 12:376-84.

17. Pescarmona E, Rendima EA, Venuta F, et al. Analysis of prognostic factors and clinicopathological staging of thymomas. Ann Thorac Surg 1990;50:534-8.

18. Shimizu N, Moriyama S, Aoe M, Nakata M, Ando A, Teramoto $S$. The surgical treatment of invasive thymoma: resection with vascular reconstruction. J Thorac Cardiovasc Surg 1992;103:41420.

19. Akaogi E, Ohara K, Mitsui K, et al. Preoperative radiotherapy and surgery for advaced thymoma with invasion to the great vessels. Am J Surg Oncol 1996;63:17-22.

20. Blumberg D, Burt ME, Bains MS, et al. Thymic carcinoma: current staging dose not predict prognosis. J Thorac Cardiovase Surg 1998;115:303-9.

21. Snover DC, Levine GD, Rosai J. Thymic carcinoma: five distinctive histological variants. Am J Surg Pathol 1982;6:451-70.

22. Suster S, Rosai J. Thymic carcinoma: a clinicopathological study of 60 cases. Cancer 1991;67:1025-32.

23. Bernatz PE, Harrison EG, Clagett OT. Thymoma: a clinicopathologic study. J Thorac Cardiovase Surg 1961;42:424-44.

24. Wilkins EW Jr, Grillo HC, Scannell JG, Moncure AC, Mathisen DJ. Role of staging in prognosis and management of thymoma. Ann Thorac Surg 1991;51:888-92.

25. Müller-Hermelink HK, Marino M, Palestro G, Schumacher U, Kirchner T. Immunological evidences of cortical and medullary differentiation in thymoma. Virchows Arch A Pathol Anat 1985; 408:143-61.

26. Müller-Hermelink HK, Marino M, Palestro G. Pathology of thymic epithelial tumors. Curr Top Pathol 1986;75:207-68.

27. Kirchner T, Schalke B, Buchwald J, Ritter M, Marx A, MüllerHermelink HK. Well-differentiated thymic carcinoma: an organotypical low-grade carcinoma with relationship to cortical thymoma. Am J Surg Pathol 1992;16:1 153-69.

28. Shimosato Y, Mukai K. Thymoma. In: Atlas of tumor pathology. Tumors of the mediastinum. Washington [DC]: The Armed Forces Institute of Pathology; 1997. p. 40-102.

29. Wilkins EW Jr, Edmunds LH, Castleman B. Cases of thymoma at the Massachusetts General Hospital. J Thorac Cardiovasc Surg 1966;52:322-30.

30. Rea F, Sartori F, Loy M, et al. Chemotherapy and operation for invasive thymoma. J Thorac Cardiovasc Surg 1993;106:543-9.

31. Macchiarini P, Chella A, Ducci F, et al. Neoadjuvant chemotherapy, surgery, and postoperative radiation therapy for invasive thymoma. Cancer 1991;68:706-13.

\section{Commentary}

The article by Okumura and associates should be compared with that of Blumberg and colleagues ${ }^{1}$ with regard to the prognostic significance of thymic tumors involving the great vessels. Both articles seem to yield the same results, despite the fact that in the current pub- 